\title{
The Secret and Beauty of Ancient Chinese Padlocks
}

\author{
Hong-Sen Yan ${ }^{1}$ and Hsing-Hui Huang ${ }^{2}$ \\ ${ }^{1}$ National Science and Technology Museum, Director General \\ 720 Chiu-Ju 1st Road, Kaohsiung 807, Taiwan \\ hsyan@mail.ncku.edu.tw \\ http: //www. acmef.org.tw \\ ${ }^{2}$ Department of Mechanical Engineering, Graduate student \\ National Cheng Kung University, 1 Ta-Hsueh Road, Tainan 701, Taiwan \\ sanly.huang@msa.hinet.net
}

\begin{abstract}
Most ancient Chinese padlocks are key-operated locks with splitting springs, and partially keyless letter-combination locks. They can be characterized based on the types of locks, the shapes of locks, the engravings of locks, the materials of locks, and the mechanisms of locks. Some locks and keys are not only very beautiful and artistic colorful, but also with various designs. As a result, a splitting spring padlock is an asymmetric key cryptosystem, and a combination padlock is a symmetric key cryptosystem.
\end{abstract}

\section{Introduction}

The development of locks arises psychologically from practical needs on safety for individuals, for groups, or for individuals within groups. Though with a long history, the related documents and perseverance of ancient Chinese locks are quite insufficient. And for their hardly noticeable nature in China, very few curio collectors set their eyes on locks, and very few scholars focused their study on locks [1, 2].

The history of Chinese locks is in close association with the materials, tools, and cultural background of a specific time. The development and applications of locks in the past reflected the technological, cultural, and economical situations of each period in the history. Ever since the late Eastern Han Dynasty, metal splitting spring padlocks had always been the most widely used locks by Chinese people. Though the shapes of ancient Chinese locks diversified, the inner structures have not changed much for the past two thousand years. And, Chinese locks faded gradually after the western pin-tumbler cylinder locks were introduced into the country in the 1940s.

This article addresses the beauty and the mechanisms of Chinese padlocks, and relates the opening systems of Chinese locks with cryptosystems.

\section{Characteristics}

Ancient Chinese locks are mechanical padlocks, mostly key-operated bronze locks with splitting springs and partially keyless letter-combination locks. The major features of ancient locks are the types of locks, the shapes of locks, the engravings of locks, the materials of locks, and the mechanisms of locks [3, 4]. 


\subsection{Types of Locks}

Ancient Chinese padlocks can be classified into the splitting spring locks and the letter-combination locks. A splitting spring padlock has to use a key for opening, and it has the types of broad locks and pattern locks. And, a letter-combination padlock has no keys for opening.

\subsection{Shapes of Locks}

Broad locks are kinds of horizontal positioned locks, Figure 1(a). The front side is of the shape of the character "凹", and mostly made of bronze. Pattern locks come in many different shapes, Figure 1(b). They can be roughly classified into the types of human figures, animals, musical instruments, letters, utensils, and others. Combination locks usually have three to seven wheels, Figure 1(c). They are of the horizontal round-pillar shape with several tunable wheels of the same size set in array on the central axis of the pillar body. Each wheel has the same amount of carved letters.

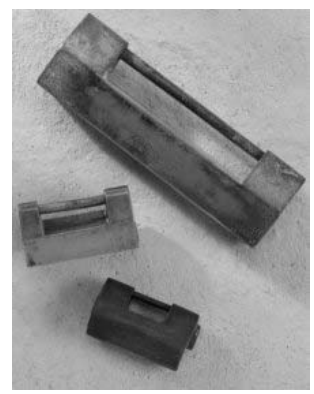

(a) Broad locks

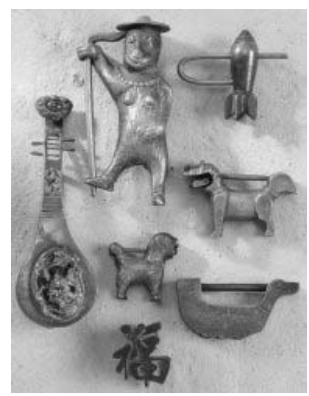

(b) Pattern locks

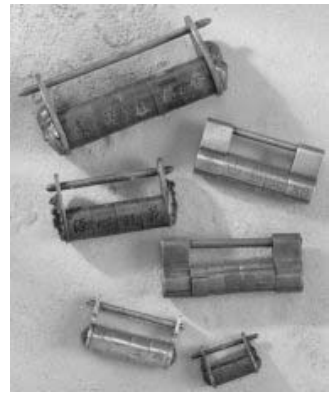

(c) Combination locks

Fig. 1. Types and shapes of Chinese locks

\subsection{Engraving of Locks}

Engraving on the body surface of Chinese locks can be classified into two types: the etching and the engraving. Patterns commonly employed are lucky objects, human figures, Chinese characters, landscapes, flowers, plants, and others. All these revealed hidden handicraft skills and great beauty in an object of such utility.

\subsection{Materials of Locks}

According to the development of various materials in various periods, ancient Chinese locks were made of wood, bronze, brass, red bronze, Cupro nickel, iron, silver, gold, steel, aluminum, and nickel. The early broad locks found were mostly made of bronze; later the brass was the most popular, followed by iron. 


\section{Mechanisms}

A splitting spring padlock consists of a lock-body, a sliding bolt, and a key, Figure 2(a). The lock-body provides a keyhole for the key to insert and the supporting guide for the sliding bolt to move. The sliding bolt has a shackle for hanging the lock and a stem for bonding one end of the splitting springs. The key is designed corresponding to the configuration of the splitting springs, and the location and shape of the keyhole. When it is locked, the sliding bolt is trapped by the opening springs against the inner wall of the lock-body. For opening, the key is inserted and its head squeezes the opening springs so that the sliding bolt can be separated from the lockbody.

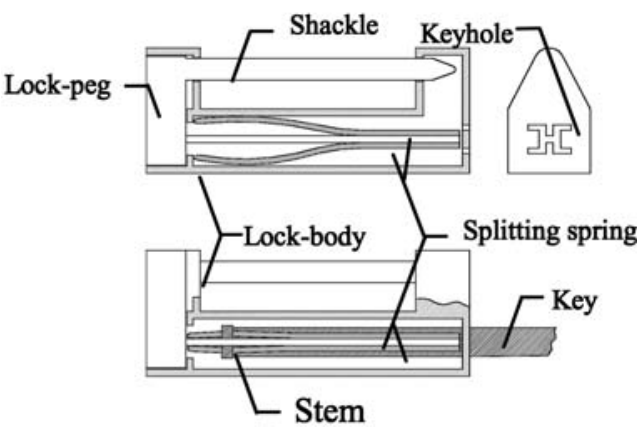

(a) Splitting-spring lock

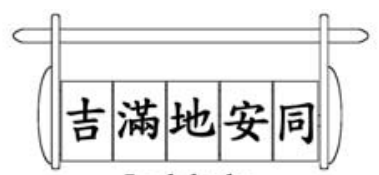

Lock-body
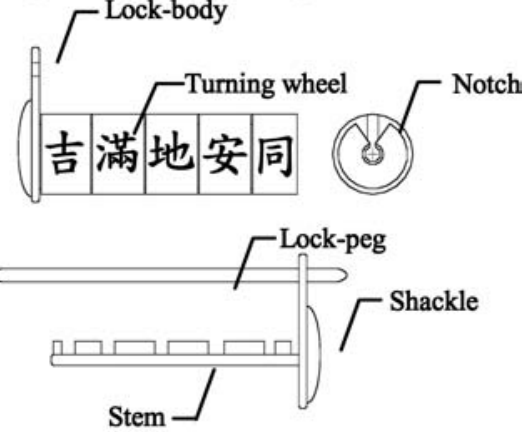

(b) letter-combination lock

Fig. 2. Mechanisms of Chinese locks

A combination padlock comprises of the lock-body, rotating wheels, and the sliding bolt with a shackle and a stem, Figure 2(b). The lock-body contains an end plate and an axis with rotating wheels for guiding the movement of the sliding bolt. The sliding bolt also has an end plate for bonding both the shackle to hang the lock and the stem with several convex (凸)-shaped blocks. Every rotating wheel is of the same size. Usually four letters are engraved on the surface. And, there is a concave (Щ)shaped chute that corresponds with each convex-shaped block on the stem. When unlocking the lock, one has to rotate the letters on each wheel into the correct order and position. When all the concave-shaped chutes face upward, a channel is formed that allows the stem with convex-shaped blocks to slide apart from the lock-body. The lock is then opened. 


\section{Cryptosystems}

A Chinese splitting spring padlock has the following features:

1. The opening key is designed to have the right shape of keyhead to be inserted through the designed shape of the keyhole and to squeeze the designed configuration of the splitting springs to open the lock.

2. It does not need the opening key to fasten the lock.

3. In general, a key is designed for a specific lock. However, sometimes a key can open more than one lock.

Therefore, a splitting spring padlock is an asymmetric key cryptosystem.

Furthermore, a Chinese combination padlock is a symmetric key cryptosystem. When the letters (ciphers) of all wheels are rotated into the right sequence, it is unlocked; otherwise, it is locked.

\subsection{Basic Components}

The mechanism of an ancient Chinese padlock has three basic components $\bullet$ fastening device, an opening device, and an obstacle.

Chinese padlocks usually use a sliding or rotary bolt as the fasten component. Most Chinese padlocks used splitting springs as the obstacle to discriminate and obstruct the wrong opening devices. In general, there are two types of obstacles. On is the fix obstacle, such as the special keyholes or keyways to prevent the invasion of foreign keys to open (decrypt) the locks. And, the other can be moved by the inserting keys to strengthen the encryption of the locks, and also to screen the wrong keys that break the first layer of security - keyholes and keyways. The opening device is used to overcome the obstacle component and can be a key or a secret code.

\subsection{Encrypt and Decrypt}

Although the coding of locks always refers to the matching design of locks and keys, it can also fit on the operation of locks. Figure 3 shows the relationship of the fastening device, the opening device, and the obstacle component that construct the operation of a lock. The opening of a Chinese lock can be taken as the key of a splitting spring padlock or the cipher of a combination padlock. When fastening the lock, the opening device should be discriminated by the obstacle to ensure the validity and encrypt the lock. If the opening device is wrong, the correct one should be renewed for preceding the encoding of the lock. Once the obstacle is overcome, the fastening device is released and the lock is in the fastening condition.

\section{Conclusions}

Although locks have been used around our daily lives in the past thousands of years, the development and characteristics of ancient Chinese locks not only have been 
almost unknown to the world but also have not been fully investigated. This paper presents the secret and beauty of ancient Chinese padlocks based on authors' study and collection in the past years [5]. Ancient Chinese locks are mostly key-operated bronze padlocks with splitting springs and partially letter-combination padlocks. Chinese padlocks can be characterized based on the mechanism of locks, the shape of locks, the type of keyways, the shape of keyways, the type of keys, the shape of keyheads, the insertion of keys, and the materials of locks. A splitting spring padlock is an asymmetric key cryptosystem, since it has to use a key for opening and it does not need the opening key to close the lock. A Chinese combination padlock is a symmetric key cryptosystem. When the letters of all wheels are rotated into the right positions, it is unlocked; otherwise, it is locked. It is hope that this article will induce further research interest to relate ancient Chinese locks and modern cryptosystems.

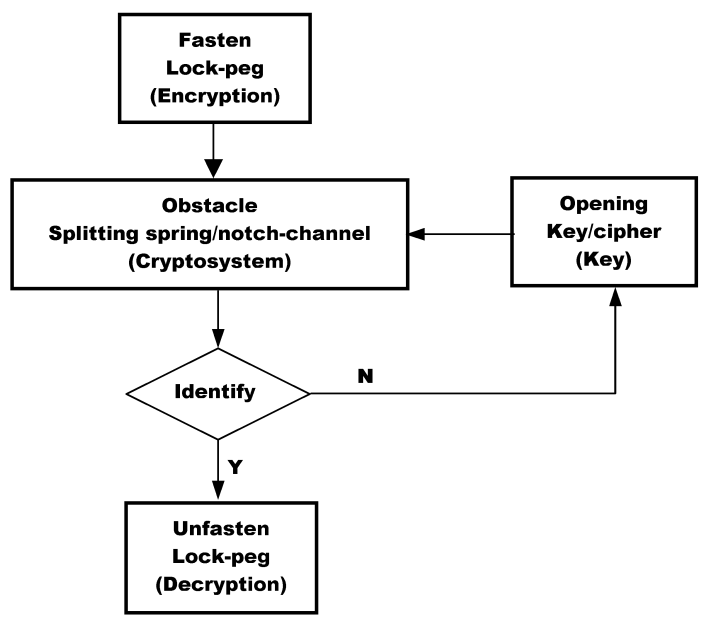

Fig. 3. Cryptosystem of Chinese locks

\section{References}

1. Joseph, N., Science and Civilization in China, Vol. IV, Cambridge University Press (1965).

2. Yan, H.S., The Beauty of Ancient Chinese Locks, 2nd edition, Ancient Chinese Machinery Cultural Foundation, Tainan, TAIWAN, ISBN 957-28702-0-X (2003).

3. Yan, H. S., "On the characteristics of ancient Chinese locks," Proceedings of the First China-Japan International Conference on History of Mechanical Technology, Beijing (1998) 215-220.

4. Yan, H.S. and Huang, H.H., "On the spring configurations of ancient Chinese locks," Proceedings of International Symposium on History of Machines and Mechanisms HMM2000, Cassino, Italy (2000) 87-92.

5. Yan, H.S., March 2003, "On the collection and research of ancient Chinese locks," Technology Museum Review, Vol.7, No.1, National Science and Technology Museum, Kaohsiung, TAIWAN (2003) 4-6. 